\title{
Identification of Sources of Resistance to Blackleg (Leptosphaeria maculans) in a Brassica napus Germplasm Collection
}

Seyedmojtaba Mansouripour and Luis E. del Río Mendoza, Department of Plant Pathology, North Dakota State University, Fargo 58108

Accepted for publication 27 April 2017.

\section{Abstract}

The increased prevalence of strains of pathogenicity group 4 of Leptosphaeria maculans, causal agent of blackleg, represents a serious threat to the canola (Brassica napus L.) industry in North Dakota, a state that contributes $>85 \%$ of U.S. canola production. The objective of this study was to identify sources of resistance to PG-4 in a collection of 559 B. napus plant introduction materials (PIs). Replicated trials were conducted twice in the greenhouse using a mixture of five PG-4 isolates to evaluate the reaction at seedling stage; then, an elite group of Pls was evaluated in replicated field trials between 2014 and 2016 at Langdon, ND, using a combination of lab-produced inoculum and blackleg-infested canola residues. Combined analysis of field data indicated three Pls had on average 73 to $80 \%$ less $(P<0.05)$ internal stem tissue discoloration than the commercial hybrids used as the controls. These Pls could be used in canola breeding programs as good sources of resistance against PG-4; in addition, efforts should be made to characterize the resistance they carry.
Blackleg, caused by the fungus Leptosphaeria maculans (Desm.) Ces. et de Not. [syn. = Phoma lingam (Tode: Fr.) Desm.], has become the most important disease affecting canola production in the United States (Fig. 1). In North Dakota, the largest canola producer in the country (USDA-NASS 2015), the disease was first observed in the early 1990s (Lamey 1995). At that time, the most prevalent $L$. maculans strains were classified as pathogenicity group (PG) 2; strains belonging to this group are incapable of affecting plants carrying resistance genes $R l m 1, R l m 2$, and/or Rlm3 (AnsanMelayah et al. 1998; Balesdent et al. 2002). The introduction of cultivars carrying these resistance genes reduced the severity and importance of this disease in the following decade (Bradley and Lamey 2005). Since then, however, the disease has steadily increased in severity and prevalence powered by the spread of strains belonging to PG-4 (del Rio Mendoza et al. 2012).

Identifying sources of resistance against PG-4 is necessary and urgent. A study published in 2010 suggested that most canola cultivars currently in use in North Dakota are susceptible to strains of PG-4. (Marino and del Rio 2010), which can overcome resistance genes Rlm1, Rlm2, and Rlm3. As PG-4 strains become more ubiquitous in North Dakota, the possibilities of severe blackleg outbreaks increase. An end-of-season survey conducted in 2014 on 114 canola fields in North Dakota revealed that blacklegsymptomatic plants were present in $96 \%$ of fields, with several having incidences greater than $30 \%$ (del Río Mendoza, unpublished data). The objective of this study was to identify B. napus germplasm that could be used as sources of resistance against PG-4 strains of L. maculans.

\section{Greenhouse Screenings}

Greenhouse screenings were intended to characterize the reaction of 559 B. napus plant introductions (PI) at the seedling stage. Seeds,

Corresponding author: Luis E. del Río Mendoza;

E-mail: Luis.delRio-Mendoza@ndsu.edu

(C) 2017 The American Phytopathological Society obtained from the North Central Regional PI Station of the U.S. National Plant Germplasm System located in Ames, IA, were planted in batches containing 29 entries at a time, with cv. Westar serving as the susceptible control. Westar is no longer a commercial cultivar and has been used as standard susceptible control because it doesn't carry known blackleg-resistance genes (Balesdent et al. 2005). Entries in each batch were evaluated using a randomized complete block design with three replications. Seeds were placed in individual plastic cells in trays $(44 \times 57 \times 50 \mathrm{~mm})$ filled with soilless potting mix (PRO-MIX BX, Premier Tech Horticulture, Quakertown, PA) and kept in greenhouse rooms at $20 \pm 2{ }^{\circ} \mathrm{C}$ with $16 \mathrm{~h}$ of light daily supplemented with 600 -watt high pressure sodium lamps (P.L. Light Systems, Inc., Beamsville, Ontario, Canada). Seedlings were inoculated, as described below, 10 days after planting when they were at the cotyledon stage. A spore suspension containing equal amounts of spores from five PG-4 isolates was used as inoculum. These five L. maculans isolates were collected in North Dakota and selected for their aggressiveness (Franceschi and del Río 2014; Franceschi 2015).

Inoculum of each L. maculans isolate was produced by culturing them in separate dishes containing V8-agar medium as described by Nepal et al. (2014). After harvest, spore concentrations of each isolate were estimated with the help of a hemocytometer, adjusted to $10^{7}$ spores $/ \mathrm{ml}$, and equal volumes of each suspension were combined for inoculations. During inoculation, the center of each cotyledon leaf was lightly pricked once with sharp forceps and a 10- $\mu$ l droplet of the spore suspension was deposited on the wound. The inoculated seedlings were incubated in cool mist chambers at $20^{\circ} \mathrm{C}$ and $98 \%$ humidity in darkness for $24 \mathrm{~h}$ and then returned to the greenhouse room.

The reaction of cotyledon leaves was recorded 10 days after inoculation based on the 0-to-9 scale of Williams and Delwiche (1979), where 0 to 3 represents a resistant reaction and 7 to 9 shows susceptibility (Fig. 2A). Levene's test for homogeneity of variances conducted on the reaction of Westar across batches indicated these batches could be combined $(P>0.05)$ for analysis. The median severity per replication for each PI was calculated using PROC MEANS of SAS v. 9.4 (SAS Institute Inc., Cary, NC) and then 
A

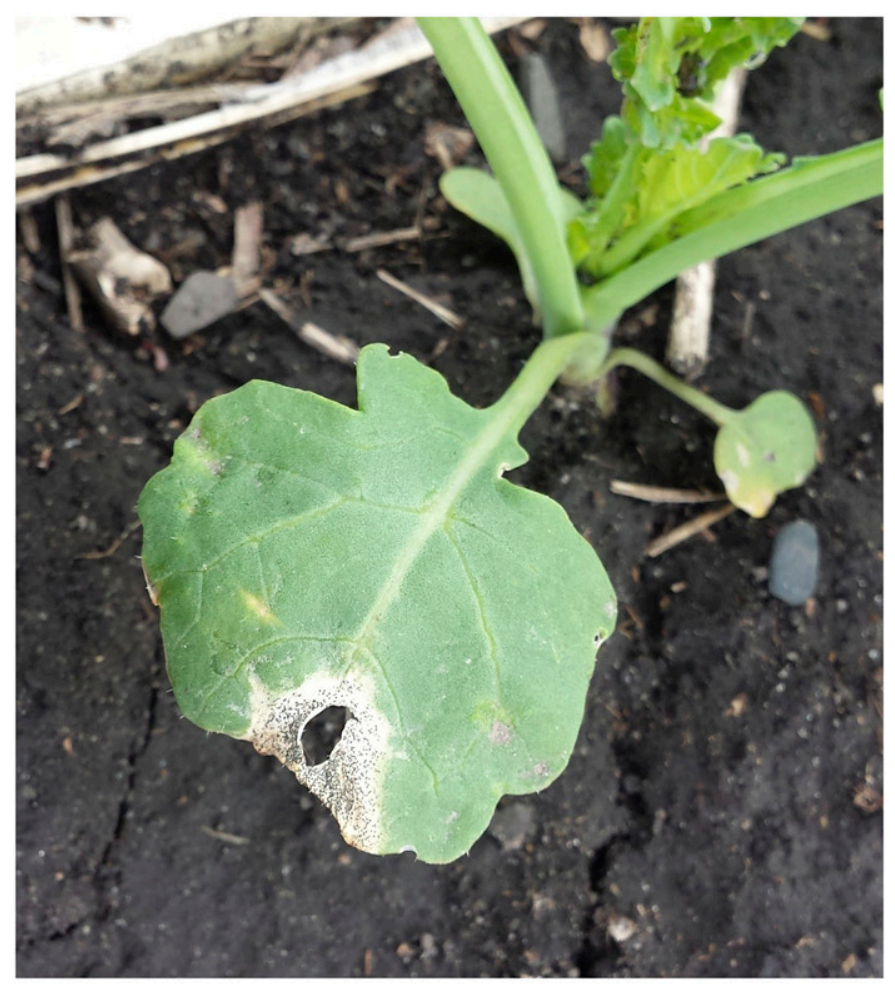

B

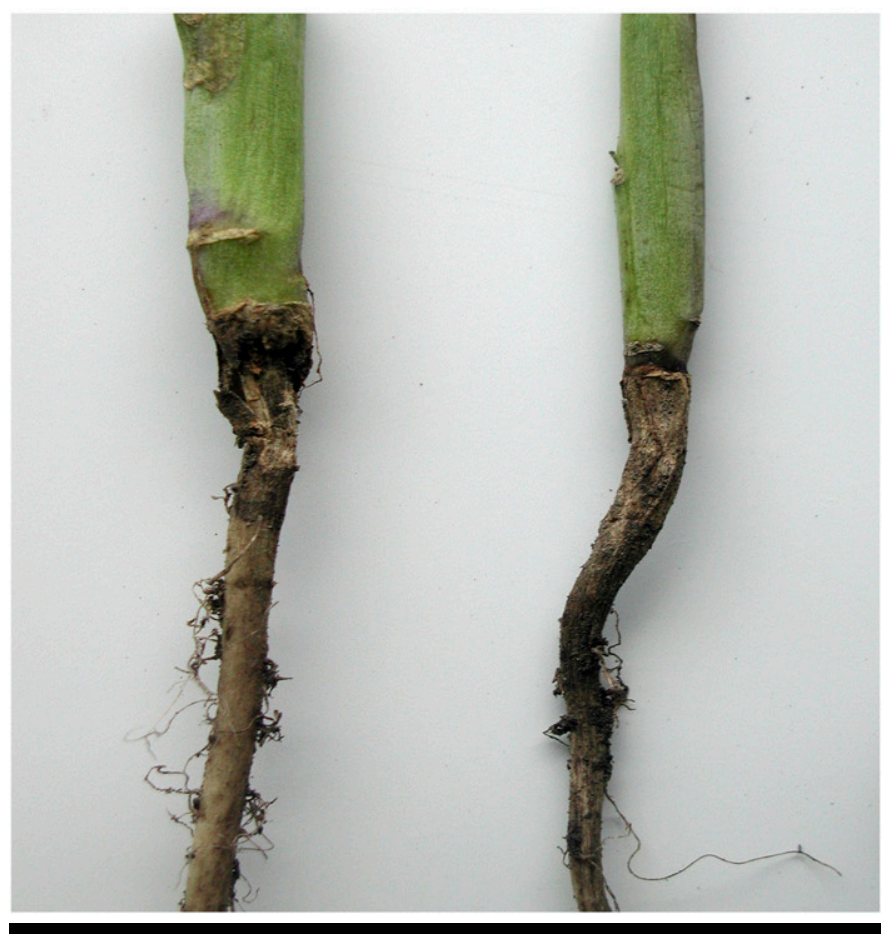

FIGURE 1

Typical blackleg symptoms caused by Leptosphaeria maculans on canola (Brassica napus) plants with lesions on (A) leaves (photo courtesy K. Chittem) and (B) stems.

ranked with respect to other accessions using PROC RANK. Ranks closest to one are associated with most resistant reactions. ANOVAtype statistic analysis was then conducted on the ranks using PROC
A

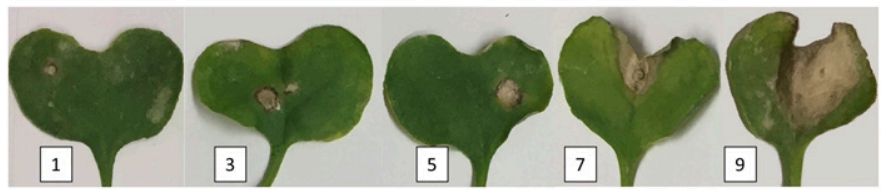

B
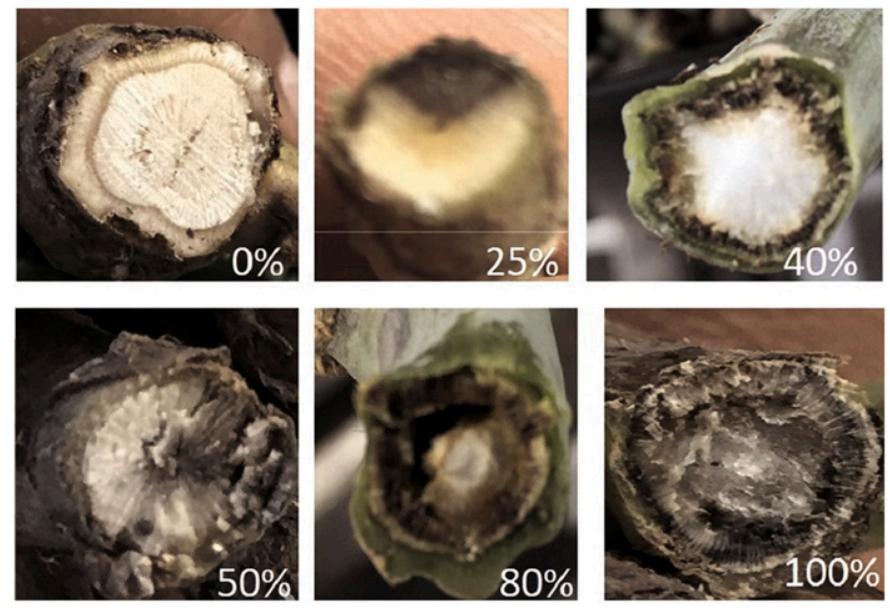

FIGURE 2

Blackleg severity scales used to evaluate damage (A) at seedling stage on cotyledon leaves and (B) at adult plant stage as percentage of internal tissues in the crown region of the stems.

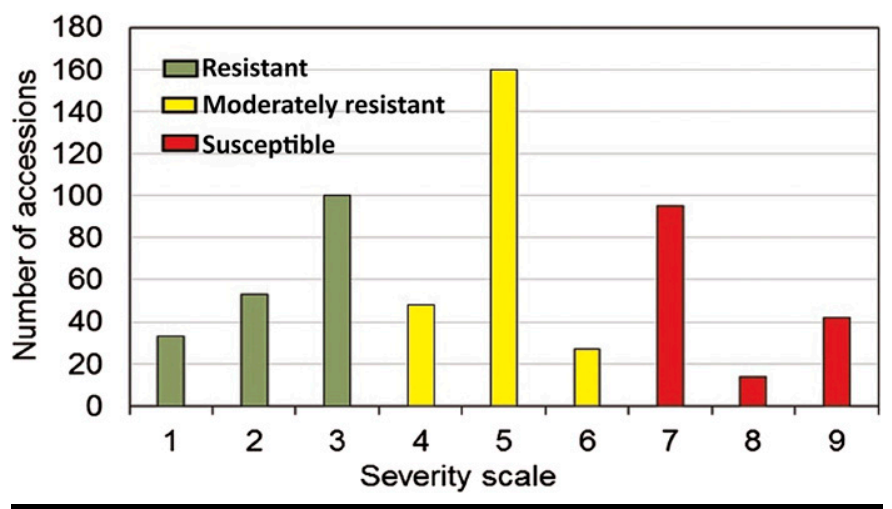

FIGURE 3

Frequency distribution of the reaction of 559 Brassica napus plant introduction materials to inoculations with a mixture of five pathogenicity group 4 strains of Leptosphaeria maculans in greenhouse trials. Reactions evaluated at seedling stage using the 0 -to- 9 severity scale of Williams and Delwiche (1979) where 0 to 3 are resistant reactions and 7 to 9 are susceptible reactions.

MIXED as described by Shah and Madden (2004). To calculate each PI's relative effect and 95\% confidence interval, the ranks were analyzed using the SAS macro LD_CI.sas from Brunner et al. (2002). The relative effects range from 0 to 1 and the values closest to zero are associated with the most resistant reactions. As a group, the PIs reaction to inoculation followed a normal distribution (Fig. 3 ) with an overall mean severity of 4.83 and a median severity of 
five. Approximately $30 \%$ of accessions were considered resistant, among which 29 PIs had medians $<3$, an indication of strong hypersensitive reactions (Table 1).

\section{Field Evaluations}

Field plots were established in 2014, 2015, and 2016 at the Langdon Research Extension Center of North Dakota State University in Langdon, ND. A total of 24 entries including 16 PG-4resistant, five PG-4-susceptible PIs, Westar as the standard susceptible control, and two commercial hybrids were planted by hand on 15, 24, and 19 May, respectively. Entries were planted in single 3 -ft-long rows following a randomized complete block design with four replications each year. Each block consisted of six tiers of four entries and two border rows. Rows were separated by $18 \mathrm{~cm}$. At least four canker-bearing canola stems collected from commercial fields in the previous growing season were deposited in each tier to provide inoculum for the plants. In addition, seedlings were sprayed at least three times between the cotyledon and three-leaf stages with a $10^{7}$ spores/ml spore suspension of the five isolates used in greenhouse screenings. The spore suspensions were prepared as described earlier and were delivered using a backpack sprayer until runoff. Disease severity was recorded when plants reached physiological maturity by cutting the stems at the crown and estimating the percentage of internal tissue discoloration (Fig. 2B). Levene's test of homogeneity of variances was conducted using PROC GLM of SAS to determine whether data could be combined for analysis. Upon confirmation of the homogeneity of variances $(P>0.05)$, a combined analysis was performed using PROC MIXED with years and replications considered random variables and entries considered fixed variables. Pairwise comparisons between least square means of PIs were estimated using the option "pdiff" in the lsmeans statement and its output analyzed using the SAS macro "pdmix800.sas" (Saxton 1998) to separate PIs using a letter system. Field trials showed significant differences $(P \leq 0.05)$ among PIs (Table 2) but not all entries performed as expected from their behavior in greenhouse trials. Thirteen of the 16 PIs considered resistant in greenhouse trials had significantly less $(P=0.05)$ disease severity than Westar, the susceptible control; however, the remaining three, Colt, Gido and Eckendorfer Mali, behaved statistically as susceptible as Westar and more susceptible than the PIs Liglandor and CR167/65a. The latter two were considered susceptible $(P=0.05)$ in the greenhouse trials.

\begin{tabular}{|c|c|c|c|c|}
\hline Response & Iapus pl & $\begin{array}{r}\text { TABLE } 1 \\
\text { materials to } \\
\text { seedlings in }\end{array}$ & $\begin{array}{l}\text { G-4 is } \\
\text { ials }\end{array}$ & phaeria maculans \\
\hline & & & & elative effect $^{\mathbf{b}}$ \\
\hline Mokpo 2 & 1 & 11 & 0.02 & $0.01-0.05$ \\
\hline Iwao natane & 1 & 16 & 0.03 & $0.02-0.06$ \\
\hline Gylle & 1.5 & 148 & 0.30 & $0.15-0.51$ \\
\hline Wira & 2 & 32 & 0.07 & $0.05-0.10$ \\
\hline Kinki 21 & 2 & 55 & 0.10 & $0.07-0.13$ \\
\hline Wichita & 2 & 48 & 0.10 & $0.05-0.17$ \\
\hline Dong Hae 16 & 2 & 54 & 0.11 & $0.07-0.17$ \\
\hline Jet Neuf & 2 & 80 & 0.15 & $0.09-0.24$ \\
\hline Liropa & 2 & 70 & 0.15 & $0.09-0.25$ \\
\hline PI 169080 & 2 & 87 & 0.16 & $0.06-0.39$ \\
\hline Armander & 2 & 71 & 0.16 & $0.06-0.37$ \\
\hline Abilene & 2 & 80 & 0.18 & $0.04-0.55$ \\
\hline France 8 & 2 & 94 & 0.20 & $0.06-0.49$ \\
\hline KS 1701 & 2 & 137 & 0.26 & $0.08-0.60$ \\
\hline Dong Hae 20 & 2 & 161 & 0.30 & $0.14-0.54$ \\
\hline Norin 35 & 2 & 155 & 0.33 & $0.15-0.59$ \\
\hline Synra & 2 & 152 & 0.33 & $0.11-0.67$ \\
\hline Ames 6073 & 2 & 162 & 0.38 & $0.05-0.88$ \\
\hline
\end{tabular}

\footnotetext{
${ }^{\text {a }}$ Medians based on the reactions on two cotyledons per plant; 10 plants per replication; three replications per trial and two trials. Reactions rated according to the 0 to 9 scale of Williams and Delwiche.
}

${ }^{\mathrm{b}}$ Mean relative effects closer to 0 are considered more resistant. 
TABLE 2

Reaction of elite ${ }^{\text {B }}$ Brassica napus plant introduction materials to Leptosphaeria maculans evaluated in field trials

\begin{tabular}{|c|c|c|c|c|c|c|c|}
\hline \multirow[b]{2}{*}{ Accessions } & \multirow[b]{2}{*}{ Median } & \multicolumn{2}{|c|}{ Treatment relative effect ${ }^{\mathbf{b}}$} & \multicolumn{2}{|c|}{ Severity $(\%)^{\mathrm{c}}$} & \multicolumn{2}{|c|}{ Incidence (\%) } \\
\hline & & Mean & $95 \%$ confidence interval & Mean & Letter group & Mean & Letter group \\
\hline Colt & 3 & 0.19 & $0.14-0.26$ & 68 & A & 94 & A \\
\hline Westar & 7.2 & 0.82 & $0.80-0.84$ & 61 & $\mathrm{AB}$ & 92 & $\mathrm{AB}$ \\
\hline Ujfertodi & 5 & 0.48 & $0.21-0.75$ & 55 & $\mathrm{ABC}$ & 84 & $\mathrm{ABCDE}$ \\
\hline Ames26653 & 7 & 0.72 & $0.50-0.87$ & 47 & $\mathrm{BCD}$ & 86 & $\mathrm{AB}$ \\
\hline Gido & 3 & 0.14 & $0.07-0.25$ & 47 & $\mathrm{BCDE}$ & 88 & $\mathrm{AB}$ \\
\hline Titus & 7 & 0.68 & $0.46-0.83$ & 46 & BCDEF & 82 & $\mathrm{ABCD}$ \\
\hline Eckendorfer Mali & 3 & 0.27 & $0.12-0.48$ & 43 & BCDEF & 81 & $\mathrm{ABC}$ \\
\hline Rico & 3 & 0.18 & $0.13-0.26$ & 42 & CDEFG & 84 & $\mathrm{AB}$ \\
\hline Laura & 3 & 0.22 & $0.18-0.26$ & 40 & CDEFG & 73 & BCDEF \\
\hline Commercial hybrid \#1 & - & - & - & 37 & CDEFG & 72 & BCDE \\
\hline Legend & 3 & 0.24 & $0.13-0.39$ & 34 & CDEFGH & 82 & $\mathrm{ABC}$ \\
\hline Target & 3 & 0.24 & $0.23-0.25$ & 31 & CDEFGHIJKL & 83 & $\mathrm{ABCDEF}$ \\
\hline Su weon cheg & 2 & 0.11 & $0.06-0.22$ & 31 & CDEFGHI & 63 & CDEF \\
\hline N001-28-246-5-4 & 3 & 0.18 & $0.13-0.26$ & 28 & EFGHIJ & 56 & DEFG \\
\hline Commercial hybrid \#2 & - & - & - & 27 & FGHIJ & 61 & CDEF \\
\hline $77-71$ & 2.5 & 0.15 & $0.08-0.25$ & 27 & DEFGHIJK & 55 & EFGH \\
\hline Nabo & 3 & 0.24 & $0.13-0.39$ & 24 & FGHIJKL & 63 & DEFG \\
\hline Liglandor & 9 & 0.94 & $0.87-0.97$ & 22 & GHIJKL & 59 & DEFG \\
\hline CR 167/65a & 7 & 0.77 & $0.67-0.85$ & 17 & HIJKL & 51 & FGH \\
\hline Oleifera & 3 & 0.23 & $0.12-0.40$ & 14 & IJKL & 54 & EFG \\
\hline Bolko & 3 & 0.17 & $0.12-0.24$ & 11 & JKL & 35 & GH \\
\hline Sumner & 3 & 0.28 & $0.14-0.48$ & 8 & KL & 36 & GH \\
\hline Aomori-1 & 2 & 0.12 & $0.06-0.22$ & 8 & $\mathrm{KL}$ & 42 & GH \\
\hline CR 165/76a & 3 & 0.38 & $0.20-0.60$ & 6 & $\mathrm{~L}$ & 31 & $\mathrm{H}$ \\
\hline
\end{tabular}

a Westar and commercial hybrids \#1 and \#2 were used as controls.

${ }^{\mathrm{b}}$ Treatment relative effects calculated for plant introductions but not for commercial hybrids (-) in greenhouse screenings.

${ }^{\mathrm{c}}$ Severity expressed as percentage of discolored internal stem tissues at crown. Means in a column with the same letter are not significantly different $(P=0.05)$ per Fisher's protected least significant difference test.

These inconsistencies in performance could be explained in part by the nature of the resistance present in them. Resistance to blackleg can be qualitative or quantitative and the genes controlling them are "generally distinct" (Delourme et al. 2006). The former, also known as race-specific or vertical resistance, is typically evaluated on seedlings in greenhouse conditions while the latter, also known as polygenic or partial resistance, is evaluated on adult plants under field conditions. By supplementing the fields with blackleg-infested canola residues, we exposed these plants to strains other than the ones used in the greenhouse screenings. While no efforts were made to identify the strains of blackleg present on the residues or in infected PIs, previous studies determined that approximately $22 \%$ of isolates retrieved from commercial canola residues do not fit the profile of any PG (Nepal et al. 2014). Among the PIs whose reaction was consistent in greenhouse and field trials, CR 165/76a, Aomori-1, and Sumner had on average 73 to $80 \%$ less disease severity and 40 to $49 \%$ less incidence than either commercial control, while Bolko and Oleifera had on average $66 \%$ less severity and $38 \%$ less incidence than one of the commercial controls and had a reaction statistically similar to the other.

\section{Conclusions}

The sources of resistance identified in this study could be a valuable tool for canola breeding programs. The top three PIs presented a consistent resistant reaction to exposure to lab- and field-produced inoculum. They were collected from different countries, which increases the possibility that the genetic bases of their resistance to blackleg may be different from one another. Also, they do not require vernalization to flower, which will facilitate the development of breeding populations adapted to the growing conditions of the region.

\section{Acknowledgments}

This work was supported by the USDA/NIFA, Supplemental and Alternative Crops Grant Program, grants 2015-38624-24214 and 2011-3862430812, and NIFA Hatch Project ND002227.

\section{Literature Cited}

Ansan-Melayah, D., Balesdent, M. H., Delourme, R., Pilet, M. L., Tanguy, X., Renard, M., and Rouxel, T. 1998. Genes for race-specific resistance against blackleg disease in Brassica napus L. Plant Breed. 117:373-378.

Balesdent, M. H., Attard, A., Kühn, M. L., and Rouxel, T. 2002. New avirulence genes in the phytopathogenic fungus Leptosphaeria maculans. Phytopathology 92:1122-1133.

Balesdent, M. H., Barbetti, M. J., Li, H., Sivasithamparam, K., Gout, L., and Rouxel, T. 2005. Analysis of Leptosphaeria maculans race structure in a worldwide collection of isolates. Phytopathology 95:1061-1071.

Bradley, C. A., and Lamey, H. A. 2005. Canola disease situation in North Dakota, U.S.A., 1993-2004. Proc. 14th. Aust. Res. Assembly on Brassicas, Port Lincoln, Australia.

Brunner, E., Domhof, S., and Langer, F. 2002. Nonparametric Analysis of Longitudinal Data in Factorial Designs. Wiley, New York. 
del Rio Mendoza, L. E., Nepal, A., and Markell, S. 2012. Outbreak of blackleg in canola in North Dakota is caused by new pathogenicity groups. Plant Health Prog. 10.1094/PHP-2012-0410-01-RS

Delourme, R., Chèvre, A. M., Brun, H., Rouxel, T., Balesdent, M. H., Dias, J. S., Salisbury, P., Renard, M., and Rimmer, R. S. 2006. Major polygenic resistance to Leptosphaeria maculans in oilseed rape (Brassica napus). Eur. J. Plant Pathol. 114:41-52.

Franceschi, J. 2015. Phenotypic characterization of Leptosphaeria maculans pathogenicity groups aggressiveness on Brassica napus. M.S. thesis. North Dakota State University, Fargo, ND.

Franceschi, J., and L.del Río. 2014. Characterization of virulence of different pathogenicity groups of Leptosphaeria maculans on Brassica napus L. Phytopathology 104:S3.42.

Lamey, H. A. 1995. Survey of blackleg and Sclerotinia stem rot of canola in North Dakota in 1991 and 1993. Plant Dis. 79:322-324.
Marino, D., and del Rio, L. E. 2010. Screening of plant introduction materials from Brassica species for resistance against PG3 and PG4 isolates of blackleg. Phytopathology 100:S77.

Nepal, A., Markell, S., Knodel, J., Bradley, C. A., and del Río Mendoza, L. E. 2014. Prevalence of blackleg and pathogenicity groups of Leptosphaeria maculans in North Dakota. Plant Dis. 98:328-335.

Saxton, A. M. 1998. A macro for converting mean separation output to letter groupings in Proc Mixed. Pages 1243-1246 in: Proc. 23rd SAS Users Group Intl., SAS Institute Inc., Cary, NC.

Shah, D. A., and Madden, L. V. 2004. Nonparametric analysis of ordinal data in designed factorial experiments. Phytopathology 94: 33-43.

Williams, P. H., and Delwiche, P. A. 1979. Screening for resistance to blackleg of crucifers at the seedling stage. Pages 164-170 in: Proc. Eucarpia Cruciferae Conference, Wageningen, The Netherlands. 